\title{
Sample Size Policy for Qualitative Studies Using In-Depth Interviews
}

\author{
Shari L. Dworkin
}

Published online: 12 September 2012

(c) Springer Science+Business Media, LLC 2012

In recent years, there has been an increase in submissions to the Journal that draw on qualitative research methods. This increase is welcome and indicates not only the interdisciplinarity embraced by the Journal (Zucker, 2002) but also its commitment to a wide array of methodologies.

For those who do select qualitative methods and use grounded theory and in-depth interviews in particular, there appear to be a lot of questions that authors have had recently about how to write a rigorous Method section. This topic will be addressed in a subsequent Editorial. At this time, however, the most common question we receive is: "How large does my sample size have to be?" and hence I would like to take this opportunity to answer this question by discussing relevant debates and then the policy of the Archives of Sexual Behavior. ${ }^{1}$

The sample size used in qualitative research methods is often smaller than that used in quantitative research methods. This is because qualitative research methods are often concerned with garnering an in-depth understanding of a phenomenon or are focused on meaning (and heterogeneities in meaning)—which are often centered on the how and why of a particular issue, process, situation, subculture, scene or set of social interactions. Indepth interview work is not as concerned with making generalizations to a larger population of interest and does not tend to rely on hypothesis testing but rather is more inductive and emergent in its process. As such, the aim of grounded theory and in-depth interviews is to create "categories from the data and then to analyze relationships between categories" while attending to how the "lived experience" of research participants can be understood (Charmaz, 1990, p. 1162).

\section{S. L. Dworkin $(\square)$}

Department of Social and Behavioral Sciences, University of

California at San Francisco, 3333 California St., LHTS \#455,

San Francisco, CA 94118, USA

e-mail: Shari.Dworkin@ussf.edu
There are several debates concerning what sample size is the right size for such endeavors. Most scholars argue that the concept of saturation is the most important factor to think about when mulling over sample size decisions in qualitative research (Mason, 2010). Saturation is defined by many as the point at which the data collection process no longer offers any new or relevant data. Another way to state this is that conceptual categories in a research project can be considered saturated "when gathering fresh data no longer sparks new theoretical insights, nor reveals new properties of your core theoretical categories" (Charmaz, 2006, p. 113). Saturation depends on many factors and not all of them are under the researcher's control. Some of these include: How homogenous or heterogeneous is the population being studied? What are the selection criteria? How much money is in the budget to carry out the study? Are there key stratifiers (e.g., conceptual, demographic) that are critical for an in-depth understanding of the topic being examined? What is the timeline that the researcher faces? How experienced is the researcher in being able to even determine when she or he has actually reached saturation (Charmaz, 2006)? Is the author carrying out theoretical sampling and is, therefore, concerned with ensuring depth on relevant concepts and examining a range of concepts and characteristics that are deemed critical for emergent findings (Glaser \& Strauss, 1967; Strauss \& Corbin, 1994, 2007)?

While some experts in qualitative research avoid the topic of "how many" interviews "are enough," there is indeed variability in what is suggested as a minimum. An extremely large number of articles, book chapters, and books recommend guidance and suggest anywhere from 5 to 50 participants as adequate. All of these pieces of work engage in nuanced debates when responding to the question of "how many" and frequently respond with a vague (and, actually, reasonable) "it depends."Numerousfactors are said

\footnotetext{
${ }^{1}$ Editor's note: Dr. Dworkin is an Associate Editor of the Journal and is responsible for qualitative submissions.
} 
to be important, including "the quality of data, the scope of the study, the nature of the topic, the amount of useful information obtained from each participant, the use of shadowed data, and the qualitative method and study designed used" (Morse, 2000, p. 1). Others argue that the "how many" question can be the wrong question and that the rigor of the method "depends upon developing the range of relevant conceptual categories, saturating (filling, supporting, and providing repeated evidence for) those categories," and fully explaining the data (Charmaz, 1990). Indeed, there have been countless conferences and conference sessions on these debates, reports written, and myriad publications are available as well (for a compilation of debates, see Baker \& Edwards, 2012).

Taking all of these perspectives into account, the Archives of Sexual Behavior is putting forward a policy for authors in order to have more clarity on what is expected in terms of sample size for studies drawing on grounded theory and in-depth interviews. The policy of the Archives of Sexual Behavior will be that it adheres to the recommendation that 25-30 participants is the minimum sample size required to reach saturation and redundancy in grounded theory studies that use in-depth interviews. This number is considered adequate for publications in journals because it (1) may allow for thorough examination of the characteristics that address the research questions and to distinguish conceptual categories of interest, (2) maximizes the possibility that enough data have been collected to clarify relationships between conceptual categories and identify variation in processes, and (3) maximizes the chances that negative cases and hypothetical negative cases have been explored in the data (Charmaz, 2006; Morse, 1994, 1995).

The Journal does not want to paradoxically and rigidly quantify sample size when the endeavor at hand is qualitative in nature and the debates on this matter are complex. However, we are providing this practical guidance. We want to ensure that more of our submissions have an adequate sample size so as to get closer to reaching the goal of saturation and redundancy across relevant characteristics and concepts. The current recommendation that is being put forward does not include any comment on other qualitative methodologies, such as content and textual analysis, participant observation, focus groups, case studies, clinical cases or mixed quantitative-qualitative methods. The current recommendation also does not apply to phenomenological studies or life history approaches. The current guidance is intended to offer one clear and consistent standard for research projects that use grounded theory and draw on in-depth interviews.

\section{References}

Baker, S. E., \& Edwards, R. (2012). How many qualitative interviews is enough? National Center for Research Methods. Available at: http://eprints.ncrm.ac.uk/2273/.

Charmaz, K. (1990). 'Discovering' chronic illness: Using grounded theory. Social Science and Medicine, 30, 1161-1172.

Charmaz, K. (2006). Constructing grounded theory: A practical guide through qualitative analysis. London: Sage Publications.

Glaser, B. G., \& Strauss, A. L. (1967). The discovery of grounded theory: Strategiesfor qualitative research. Chicago: Aldine Publishing Co.

Mason, M. (2010). Sample size and saturation in PhD studies using qualitative interviews. Forum: Qualitative Social Research, 11(3) [Article No. 8].

Morse, J. M. (1994). Designing funded qualitative research. In N. Denzin \& Y. Lincoln (Eds.), Handbook of qualitative research (pp. 220235). Thousand Oaks, CA: Sage Publications.

Morse, J. M. (1995). The significance of saturation. Qualitative Health Research, 5, 147-149.

Morse, J. M. (2000). Determining sample size. Qualitative Health Research, 10, 3-5.

Strauss, A. L., \& Corbin, J. M. (1994). Grounded theory methodology. In N. K. Denzin \& Y. S. Lincoln (Eds.), Handbook of qualitative research (pp. 273-285). Thousand Oaks, CA: Sage Publications.

Strauss, A. L., \& Corbin, J. M. (2007). Basics of qualitative research: Techniques and procedures for developing grounded theory. Thousand Oaks, CA: Sage Publications.

Zucker, K. J. (2002). From the Editor's desk: Receiving the torch in the era of sexology's renaissance. Archives of Sexual Behavior, 31, $1-6$. 